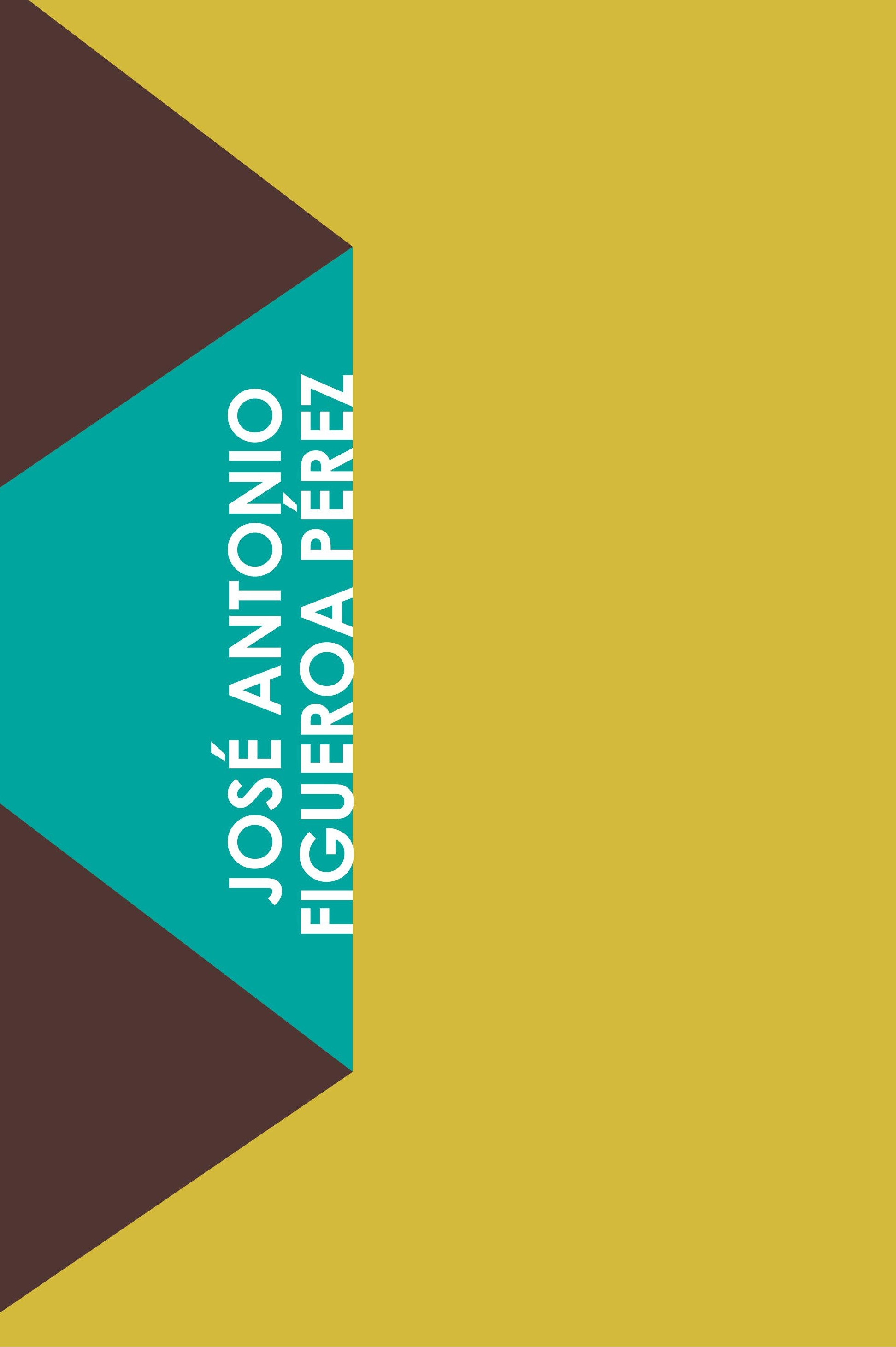




\section{Horamen de Adrián Balseca y la desposesión neocolonial en La Tolita, Esmeraldas}

\section{Adrián Balseca's Horamen and the neocolonial dispossession in La Tolita, Esmeraldas}

\section{José Antonio Figueroa Pérez}

ISSN (imp): 1390-4825

ISSN (e): 2477-9199
Fecha de recepción: 15/03/18 Fecha de aceptación: 13/05/18

\section{Resumen:}

A partir de la obra Horamen, del artista Adrián Balseca, que sintetiza la expoliación que ha sufrido la isla La Tolita en Esmeraldas, el artículo reflexiona sobre el impacto de la desposesión en el modo de organización del trabajo y de la sociedad, en una región patrimonial densamente sometida a la experiencia colonial, principalmente por razones raciales.

\section{Pallabras clave:}

Adrián Balseca, Horamen, desposesión, Esmeraldas, racismo.

\section{Biografía del Autor:}

\section{Abstract:}

This paper analyzes the work "Horamen" of the Ecuadorian artist Adrián Balseca, which summarizes the plundering in the island of Tolita, Esmeraldas, one of the most important archeological sites in Latin America. The article shows how poverty plays a crucial role on the organization of work and society in a region that has been heavily subjected to colonial experience, mainly for racial reasons.

\section{Key Words:}

Adrián Balseca, Horamen, dispossession, Esmeraldas, racism

Universidad Central del Ecuador. jafigueroa@uce.edu.ec 


\section{INTRODUCCIÓN}

En el año 2014, el artista Adrián Balseca llegó a la Bienal de Cuenca llevando a rastras un viejo carro Andino Miura del año 1977, al que quitó el tanque de gasolina y empujó durante seis días desde Quito, recorrió así más de 400 kilómetros hasta el salón de la bienal. Ayudado por otros conductores, empujado por burros y por tracción humana, la eliminación del tanque ratificaba que por sus solas condiciones mecánicas el vehículo no hubiera llegado hasta ahí. El uso de tecnologías alternativas para movilizarlo evocaba también la economía extensiva, propia de las plantaciones, de las haciendas y de las zonas extractivas, donde la falta de especialización y de eficiencia tecnológicas se sustituye por el uso amplio de una mano de obra obligada a realizar cualquier tarea que vaya surgiendo en la jornada.

Hacia los años setenta, en el Ecuador, la economía extensiva, propia de las haciendas serranas, se había agotado. El gobierno militar de Rodríguez Lara gobernaba en un contexto de transformaciones agrarias y de una retórica desarrollista. En medio del furor petrolero, la fabricación del carro presagiaba la creación de una industria automotriz nacional que representaba la joya del desarrollo para unas elites seguidoras del modelo norteamericano. Las ilusiones de las elites se mantenían, a pesar de que el proyecto estaba limitado a producir partes y la fabricación del motor continuaba en manos de la Vauxhall, la compañía inglesa de la cual los promotores del proyecto eran los distribuidores. La elección del nombre, Andino Miura, evocaba también la elección de la identidad de clase de las élites quiteñas, que habían encontrado en los toros de lidia de origen español, uno de los símbolos más fuertes de su cohesión simbólica. (Ver figura 1)

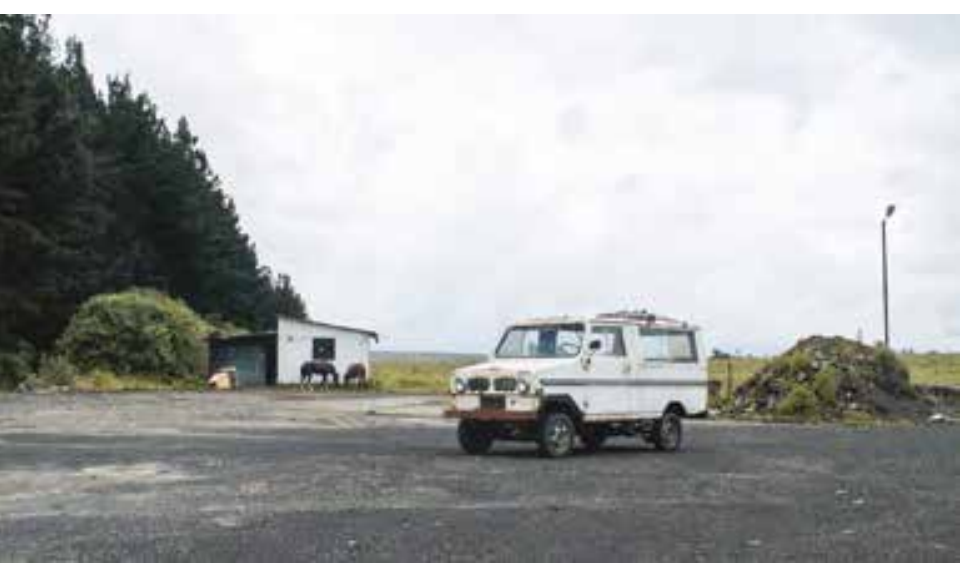

1. A medio camino (fotograma), Adrián Balseca, 2016. Cortesía del artista.
El fracaso del Andino que Balseca evoca con su obra, señala la dificultad de construir soberanía tecnológica en países con fuertes nexos de dependencia. Un antecedente de este fracaso ocurrió con el tren nacional, el tranvía de Quito y la posterior imposición de un sistema de buses vinculado a lógicas corporativas opuestas al interés público (Figueroa, 2008; Clark, 2001; Quintero y Silva, 2001). Con esta obra, Balseca nos muestra los límites de una modernidad periférica en la que la construcción del vehículo aparece como un hecho incompleto y aislado, incapaz de generar efectos en cadena que transformen el aparato productivo nacional. Más recientemente, Balseca nos invitó de nuevo a reflexionar sobre las características de nuestras modernidades periféricas desde un lugar más dramático, que podríamos catalogar como la periferia de la periferia, porque en él se concreta en toda su profundidad la experiencia interno colonial: me refiero a su pieza Horamen, que se exhibió en el año 2017, en el Museo Casa del Alabado de Quito (Ver figura 2), que sintetiza visualmente el despojo del patrimonio arqueológico de la isla La Tolita y devela algunos de los efectos del colonialismo interno, que ha caracterizado históricamente a la provincia de Esmeraldas (Minda, 2002 y Figueroa, 2017).

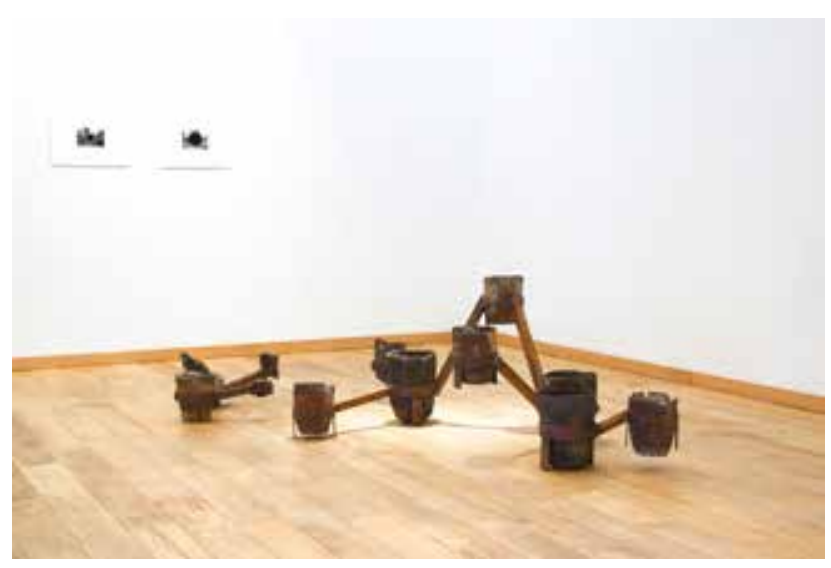

2. Vista de Horamen en el Museo de Arte Precolombino Casa del Alabado. Foto: Martina Orska, 2017. Cortesía Museo de Arte Precolombino Casa del Alabado.

Horamen evoca el modo de organización del capitalismo en una de sus múltiples periferias (cfr. Stoler, 2013) y ayuda a entender el despojo como un acumulado de hechos históricos, permanentemente actualizados e inacabados (Stoller, 2013 y Ojeda, 2017) que incluyen la extracción inmisericorde de recursos y la utilización precaria de la mano de obra. En La Tolita se muestra cómo el despojo y la ruina limitan a las comunidades en el manejo de sus recursos y de sus formas de vida $y$ 


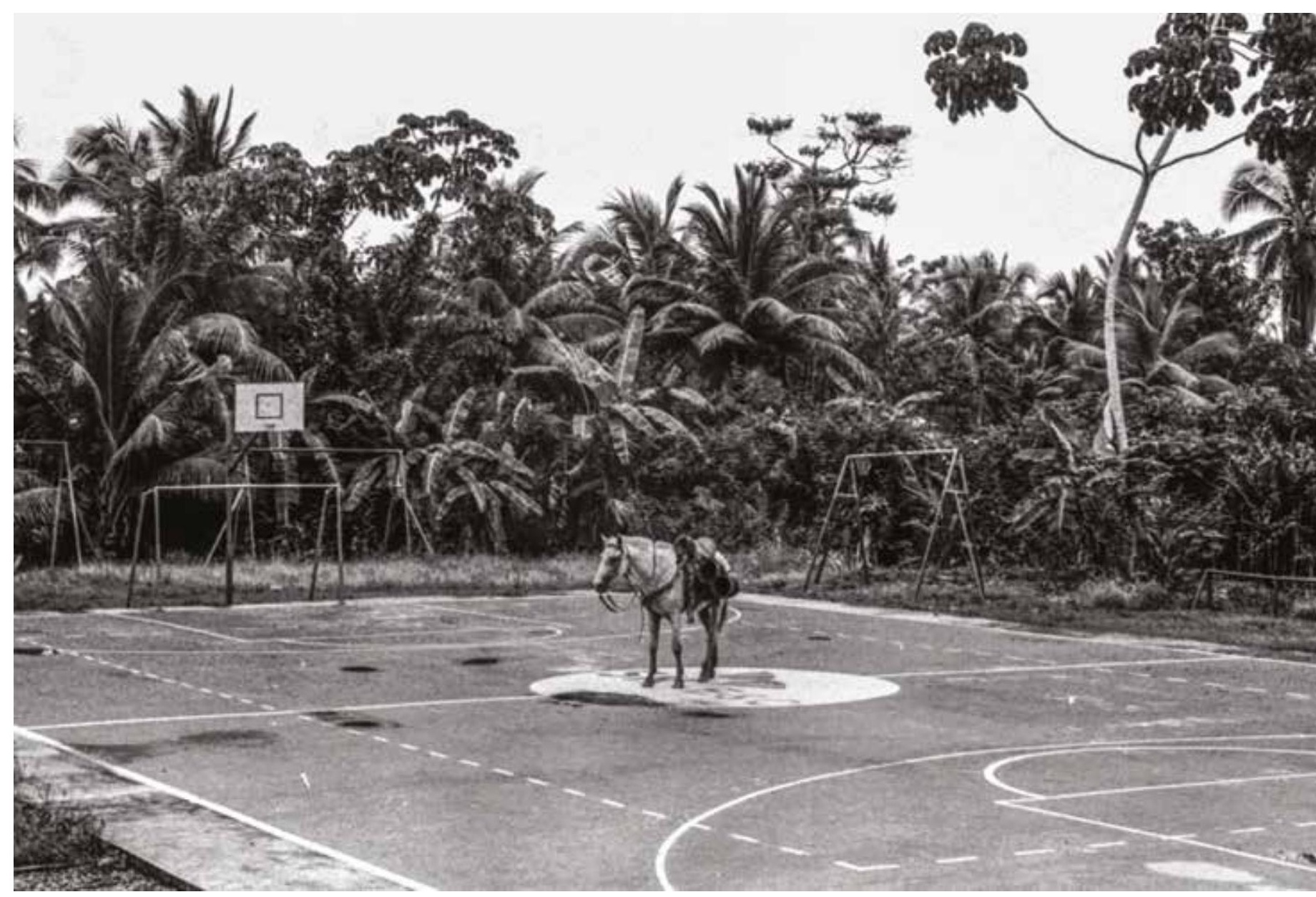

3. H-2 (Horamen), Adrián Balseca. Cortesía del artista, 2017.

les obliga a resignificar el espacio (Ojeda, 2016). La expoliación del oro de La Tolita muestra una fase de la circulación de los recursos que alimentaron al capital privado nacional e internacional y a las reservas de oro del Banco Central del Ecuador, y devela las conexiones globales del capitalismo (Coronil, 2007), que fomentan la coexistencia de formas abyectas de trabajo con la más avanzada organización tecnológica y social.

En este trabajo propongo leer Horamen en el contexto de desposesión de la isla de La Tolita y de la economía interno colonial de Esmeraldas (Ver figura 3). Propongo contrastar las contribuciones de Glissant (2015), quien analiza la desposesión desde una serie de hábitos sociales y culturales que se expresan en sociedades, regiones o países coloniales y neocoloniales que sufren la expoliación, con los conceptos de Harvey (2004) sobre la acumulación por desposesión, para mostrar cómo el saqueo del patrimonio arqueológico de La Tolita y las formas laborales para ese fin expresan el modelo interno colonial que continuó en Esmeraldas, luego de la derrota del liberalismo radical en 1912 (Figueroa, 2017). La expoliación temprana de La
Tolita es una consecuencia de la derrota de los radicales afroesmeraldeños que buscaban cambiar las condiciones interno coloniales de la provincia y el precarismo laboral al que se sometía a la población. La derrota del radicalismo permitió que en Esmeraldas se profundizara el carácter extractivista y el precarismo, impuesto principalmente sobre la población afrodescendiente. El artículo indaga la tensión entre las dinámicas de la modernidad, que Berman (1991) denomina pastorales y contrapastorales, en el contexto de la periferia y que se expresan por igual en la tecnología, las artes y las ciencias. En su perspectiva, las pastorales del capitalismo, derivadas de su expansión, estimulan un ritmo de desarrollo que se sintetiza en la frase de Marx de que "todo lo sólido se desvanece en el aire" y han encontrado apoyo en vanguardias fascinadas por la tecnología. De otro lado, están las contrapastorales, asociadas al carácter agonístico del consumo, que promueven imágenes escépticas y temerosas frente a la cara destructiva del progreso. Este trabajo propone indagar las implicaciones de las contrapastorales en el contexto de modernismos periféricos como el de nuestros países. 
Mientras que las técnicas culturales de detección de las fuentes de oro se remiten a los sueños. Varios de los testimonios de Rivera Fellner (2014) refieren que muchos hallazgos de piezas proceden de sueños en los que las almas de los indígenas cuentan dónde están los entierros. Otros hallazgos se hacen mediante la toma de ayahuasca, la banisteriopsis spp, localmente conocida como puildé; Quienes participan en los viajes shamánicos tienen visiones en las que aparecen almas de los antiguos habitantes de La Tolita. En estos casos, las visiones se asocian a una liberación de almas condenadas, lo cual, como se verá, guarda analogías con los casos vistos por Michael Taussig en el contexto de las explotaciones del Valle del Cauca, en Colombia.

¿Qué condiciones posibilitaron esa forma de explotación de los recursos de La Tolita y el reclutamiento de esa mano de obra para un trabajo tan precario? Para una somera respuesta, basta decir que hacia los años veinte en Esmeraldas continuaba una economía extractivista de larga duración que la población afroesmeraldeña venía disputando desde el período colonial. Pocos años antes, esta población había apoyado una insurrección armada, conocida como La Guerra de Concha, en la que contingentes afroesmeraldeños tuvieron un papel protagónico aglutinados en torno a la lucha por la libertad. Este contingente fue derrotado en un levantamiento armado que duró entre 1912 y 1916.

La irrupción de la guerra sintetizaba una larga historia de creación de una conciencia política afroesmeraldeña, en medio de tensiones entre sus reclamos de libertad y la imposición de la sujeción forzosa, tanto por parte de la Corona española en el período colonial, como de las autoridades nacionales posindependentistas y republicanas. Mientras en el contexto colonial, los afroesmeraldeños negociaron con la Corona ciertos privilegios por vigilar a los propietarios de las minas que intentaban evadir las obligaciones fiscales (Rueda, 2010; Morelli, 2016), en el contexto posindependentista se encontraron con una serie de frustraciones: las promesas de emancipación se pospusieron mediante el decreto de la libertad de vientres, que privilegiaba el interés de los esclavistas, y luego, a partir de mediados del siglo XIX, cuando se declara la manumisión, el estado reactivó las formas precarias de trabajo y el extractivismo de la región, al entregar inmensas extensiones de la provincia a la compañía Inglesa Ecuador Land Company, en compensación por las deudas contraídas en la independencia (De la Torre y Del Arco Proaño, 2015, p. 144). La apertura a manos privadas de propietarios de la sierra y de extranjeros, la especialización extractivista de productos para el mercado internacional (como la tagua y el caucho) junto a la consolidación del concertaje, reactivaron el esclavismo y la desposesión territorial de la región. En este contexto se produjo la revolución liberal, la muerte de Eloy Alfaro y la guerra de los afroesmeraldeños que, una vez derrotados, experimentaron los efectos de la apropiación territorial por parte de afuereños y la explotación de los recursos, como sucedió en La Tolita.

\section{LA TOLITA Y LA DES-ACU- MULACIÓN ORIGINARIA}

Los estudios contemporáneos sobre la desposesión, la expoliación y la ruina de la experiencia colonial y neocolonial, evidencian que la acumulación originaria, señalada por Marx, es un fenómeno permanente en el capitalismo (Stoller, 2013). También, los estudios sobre el despojo y la desposesión, desde la teoría crítica postcolonial, muestran la coexistencia en el capitalismo de las formas más avanzadas de organización del trabajo y de la tecnología con las formas más espurias de utilización de la mano de obra y del desarrollo tecnológico, como en La Tolita. Así, las aproximaciones a los modos de organización del trabajo y de la sociedad en las modernidades periféricas, no permiten definir al capitalismo periférico como alternativa exógena al capitalismo central, sino que nos obligan a entender el papel de la coexistencia de las formas más avanzadas y las más espurias de organización social y tecnológica como hechos constitutivos del capitalismo global.

De igual manera, la constatación de la coexistencia ,cada vez mayor en el denominado primer mundo, de formas avanzadas y espurias de organización del trabajo y de la tecnología, y el carácter racializado de estas divisiones, devela la capacidad del capitalismo de incluir en el despojo a sitios que se suponían intocables por su localización en el capitalismo central. Los análisis de Harvey (2004) sobre la acumulación por desposesión muestran cómo la permanente crisis de sobreacumulación que vive el capitalismo desde la década de los setenta determina una reconfiguración social, espacial y cultural del capitalismo tardío, que busca garantizar la libre movilidad del capital y la ganancia especulativa a través del despojo y la desposesión a nivel planeta- 
rio, lo cual ha venido acompañado de unas lógicas de desregulación evocadoras de las fases de acumulación originaria del capital.

De otro lado, una rica literatura sobre el sur global y especialmente de Suramérica y El Caribe (Glissant,2014; Gramsci, 1980; Mariategui, 1982) y estudios contemporáneos sobre la desposesión (Stoler, 2013; Hart 2016; Arias y Caicedo, 2016; Ojeda, 2016) permiten entender las formas como opera lo que, parafraseando a Harvey (2004), podríamos llamar la desacumulación por desposesión. En este sentido, terminaré este artículo mostrando cómo ciertas características del modo de organización del trabajo, en un contexto de desposesión como La Tolita, guarda grandes analogías con lo establecido por Glissant (2014), en la experiencia colonial en Martinica- y por Taussig (1977)- entre los trabajadores afrocolombianos de las zonas cañeras. Estas aproximaciones nos permiten leer algunas de las concepciones inherentes a la mercancía, a la sociedad y a la tecnología en contextos de desposesión como de La Tolita.

De acuerdo con Glissant (2014), uno de los principios en los que se fundamenta la desposesión es el de quitar a los trabajadores el control de lo que sucede con la producción: por ejemplo, evitar que los trabajadores tengan contacto con el mercado, por lo que eventualmente recurren al contrabando, lo cual los convierte en vulnerables, o cuando se produce una débil o inexistente monetarización de las relaciones laborales que hacen al trabajador más dependiente de la bondad del patrón. En La Tolita situaciones similares aparecen registradas en testimonios que muestran cómo allí se implementó por parte de Yanuzzelli el mismo sistema de deudas de las haciendas serranas, que enclaustraban las relaciones económicas de los trabajadores exclusivamente con los propietarios de la isla, con los que mantenían una deuda permanente y evitaron que el trabajador tuviera alguna posibilidad de acumulación, de previsión o de tecnificación (Glissant, 2014:55).

Varios de los testimonios recogidos por Rivera Fellner (2012) muestran cómo en La Tolita se creó una economía de supervivencia con todos los rasgos que le imputa Glissant: la economía de la zona generó formas de resistencia social de matriz conservadora, se creó una marginación incapaz de crear comunidades alternativas, en tanto estas se encontraron limitadas a activar instintivamente a su propia supervivencia y crearon hábitos fragmen- tados, que dificultaron incluso la creación de tradiciones, e, igualmente, tampoco condujeron

(...) a la sedimentación de prácticas técnicas, cuyo conocimiento y cuyo peso habrían llevado a progresos colectivos. La función técnica se ve frecuentemente saturada de gestos supersticiosos que compensan ese no control colectivo y que al final, más que unir, dividen.... la supervivencia lleva así su propio límite: se trata de un instinto de fraccionamiento... Y lo cierto es que toda iniciativa de estructurar una iniciativa... parcial de supervivencia resultará, una vez más, vana y estéril (es decir, incapaz de concebir a la comunidad) si esta iniciativa no está orientada por una verdadera teoría general de la supervivencia como un conjunto no parcelado de resistencias convergentes (Glissant, 2014).

El antropólogo Michael Taussig indagó cómo el proletariado negro del Valle del Cauca conceptualizaba, en términos culturales, unas relaciones laborales marcadas por la desposesión, y encontró dos prácticas significativas: los pactos con el demonio y el bautizo del billete. En el primer caso, se creía que algunos de los trabajadores establecían pactos secretos con el demonio con el objetivo de incrementar sus riquezas. Estos trabajadores, cuya característica común era la de no tener ninguna propiedad, estaban tentados por el demonio, a venderles sus almas a cambio de tener ingresos extra durante un tiempo de su vida, pero para lo cual morirían en agonía e irían al infierno.

En la ceremonia del bautizo del billete, los padrinos, de manera camuflada, llevan un billete de un peso que es el que recibe el bautizo y el nombre que iba a ser dado al ahijado, El billete se carga de un poder mágico, que hace que en cualquier transacción monetaria, ese peso retorne multiplicado varias veces. Cuando el poseedor del billete realiza la transacción de manera disimulada le pregunta: "X.. te vas o te quedas? ¿Te vas o te quedas? ¿Te vas o te quedas?”. Y espera que el billete regrese multiplicado, mientras el niño una vez muere irá indefectiblemente al purgatorio o al infierno. Tausssig (1977) analiza los casos del proletariado caucano desde el concepto de fetichismo de Marx. El fetichismo, sabemos, es la creencia de que el valor de la mercancía se da por la relación que las cosas sostienen entre ellas, y oculta que el creador de valor es el trabajo humano. 
Para Taussig (1977), el fetichismo de la mercancía es algo que se comparte en todas las sociedades, sin embargo, donde no hay relaciones salariales plenas, como en las sociedades neocoloniales del Valle del Cauca o de La Tolita, los sujetos no conciben la posibilidad de que el capital se reproduzca por sí mismo, y si lo hacen lo entienden con sentimientos encontrados de culpabilidad.

La forma más contundente del fetichismo de la mercancía se da en la fase ampliada en la que el capital es capaz de crear más capital. En este caso, se experimenta la frase de Marx que dio título al libro de Berman: "todo lo sólido se desvanece en el aire", cuando se experimenta la destrucción creadora en la que no hay tecnología que no sea permanentemente sometida a su propia destrucción. Por el contrario, en sociedades de desposesión, sin mercado y sin relaciones salariales claras, donde predomina la relación mercancía-dinero-mercancía se necesita una intermediación fetichista de otro orden, en este caso religiosa, para poder aceptar el carácter reproductivo del dinero. En La Tolita, coexisten dos maneras de concebir la mercancía en un contexto de desposesión: una, la de los saqueadores nacionales, incluido el Estado, que se articulan al mercado nacional e internacional en niveles especulativos, que no dejan nada en el sitio que explotan; la otra, la de los trabajadores locales, que han estado marginados de las relaciones salariales plenas y quienes conciben el acceso a la riqueza como un favor que hacen al alma de los indios muertos y creen que, en el fondo, también se condenan ellos, por lo que tendrán que ser salvados por alguien más. Este sistema de creencias aparece como un sustituto de la articulación al mercado y expresa un desarrollo tecnológico espurio. Es, a su vez, la manera como una comunidad local sometida a la experiencia de la desposesión se articula con un hecho económico que va más allá de su territorialidad.

\section{BIBLIOGRAFÍA:}

Balseca, A. (2017). Horamen Zarigueya Alabado contemporáneo. Quito: Museo de Arte Precolombino Casa del Alabado.

Berman, M. (1991). Todo lo sólido se desvanece en el aire. La experiencia de la modernidad. Bogotá: Siglo XXI.

Clark, K. (2004). La obra redentora. El ferrocarril y la nación en ecuador 1895-1930. Quito: Universidad Andina Simón Bolívar - Cor- poración Editora Nacional.

Coronil, F. (2007). Editor's Column: The End of Postcolonial Theory?. Modern Language Association, (122) 633-651.

De la Torre, A. y Nuñez del Arco, F. (2015). Land Company Limited: dependencia y cesión de soberanía en: Monopolios y Poder en la Historia del Ecuador. Quito: Ministerio de Cultura.

Ferdon, Edwin N. Corbett, J. (1941). Depósitos arqueológicos de La Tolita. Boletín de la Academia Nacional de Historia, 21 (57), p. 5-15.

Figueroa J. (En evaluación). Raza y Silenciamiento Politico, novela, historia y prensa en la guerra de los afroesmeraldeños.

Figueroa J. (2009). Realismo mágico, vallenato y violencia politica en el caribe colombiano. Bogotá: Icanh.

Figueroa J. (2008). Sistemas públicos deficitarios en modernidades periféricas. Reflexiones sobre la historia del tren y del tranvía en Ecuador y Quito. El Camino de Hierro. Cien años de la llegada del ferrocarril a Quito. Quito: FONSAL.

Glissant, E. (2015). El discurso Antillano. Guayaquil: Uartes.

Gramsci, A. 1980. Selections from the Prison Notebooks. Nueva York: I.P.

Harvey, D. (2004). "The 'New' Imperialism: Accumulation by Dispossession”. Socialist Register (40), p.63-87.

Minda, P. (2002). La lucha por la tierra en la zona norte de la provincia de Esmeraldas. Quito: UPSQ, Abya Yala,

Morelli, F. (2016) Guerras, libertad y ciudadanía. Los afro-descendientes de Esmeraldas en la independencia. Revista de Indias, (LXXVI, n. ${ }^{\circ}$ 266) p.83-108. Los paisajes del despojo: propuestas para un análisis desde las reconfiguraciones socio-espaciales. Revista Colombiana de Antropología, 52 (2), p.19-43.

Quintero R. y Silva E. (2001). Ecuador. Una nación en ciernes. Quito, Editorial. Universitaria.

Rivera Fellner, M. (2012) Identidad y patrimonio arqueológico. El caso de La Tolita Pampa de Oro (Ecuador). Quito, Ecuador: Flacso.

Rueda Novoa, R. (2010). De esclavizados a comuneros en la cuenca aurifera del río Santiago Cayapas (Esmeraldas), etnicidad negra en construcción en Ecuador siglos XVIII-XIX. (tesis doctoral), Unversidad Pablo de Olavide, Sevilla, España. 
José Antonio Figueroa Pérez

Stoler, A.(ed.) (2013). Imperial Debris On Ruins and Ruination. Durham y Londrés: Duke University Press.

Taussig, M. (1977). The Genesis of Capitalism amongst a South American Peasantry: Devil's Labor and the Baptism of Money. Comparative Studies in Society and History, 19 (2), p. 130-155. 